\title{
IMPACTOS HIDROMETEÓRICOS EM BELO HORIZONTE-MG
}

\author{
LUCAS, Taíza de Pinho Barroso - taizaead@gmail.com \\ Docente do Centro Federal de Educação Tecnológica de Minas Gerais - CEFET-MG. \\ Doutoranda em Geografia, IGC/UFMG.
}

AUGUSTO, Pollyanna - polly_augusto@hotmail.com Geógrafa, Centro Universitário de Belo Horizonte

REIS, Stefany dos - stefany_reisramos@hotmail.com Geógrafa, Centro Universitário de Belo Horizonte

ROCHA, Solimar Carnavalli - solcarnavalli@hotmail.com Geógrafa, Centro Universitário de Belo Horizonte

\begin{abstract}
RESUMO: A finalidade do estudo é apresentar os impactos hidrometeóricos ocorridos entre 2009-2012 e espacializar os registros de impactos, em novembro de 2010, na cidade de Belo Horizonte, que ocasionaram alagamentos e inundações em vários bairros, provocando danos em residências e vias públicas. A partir da Planilha de Inundação da Coordenadoria Municipal de Defesa Civil (COMDEC) foram identificados os bairros atingidos por eventos de enchentes e/ou inundações e alagamentos. Os resultados foram apresentados através de gráficos e mapas, sendo a estação chuvosa 2010/2011 o período de maior ocorrência. As Regionais Norte e Pampulha, apesar das diferenças de dinâmica populacional e padrão urbanístico, foram as mais afetadas e mesmo com diminuição de casos de enchentes e/ou inundações em 2011 e 2012, o número de alagamentos triplicou no último ano. A espacialização dos casos de inundação e risco de inundação, alagamentos e risco de alagamento mostram que os bairros mais afetados situam-se nas Regionais Oeste, Noroeste e Pampulha, particularmente pelas características físicas da bacia do Onça.
\end{abstract}

PALAVRAS-CHAVES: Impactos hidrometeóricos, espacialização, Belo Horizonte. HYDROMETEORIC IMPACTS IN BELO HORIZONTE-MG

ABSTRACT: The purpose of the study is to present the hydro-meteoric impacts which happened between 2009 and 2012 and to spatialize the impacts records, in November of 2010, in the city of Belo Horizonte, which caused inundations and flooding in several neighborhoods, provoking damage in residences and public roads. From the Municipal Civil Defense Coordination (COMDEC) Inundation Spreadsheet were identified the neighborhoods reached by inundations and flooding. The results were presented through graphics and maps, being 2010/2011 rainy season, the period with the greatest occurrence. Norte and Pampulha regions, despite its populational dynamic and urbanistic standard differences, were the most affected and even with decrease cases of flooding and inundations in 2011 and 2012, the number of flooding tripled in the last year. The inundation and inundation risk, flooding and flooding risk spatialization cases show that the most affected neighborhoods are located in Oeste, Noroeste and Pampulha Regions, especially because of Onça basin physical characteristics.

KEYWORDS: Hydro-meteoric impacts, spatialisation, Belo Horizonte.

\section{INTRODUÇÃO}

A urbanização deflagrou uma intensa transformação no espaço urbano das grandes cidades no Brasil nos últimos 60 anos. A partir da década de 1950, 
houve um crescimento explosivo das capitais brasileiras devido ao grande crescimento demográfico que ocorreu para atender às necessidades de mão de obra da eminente industrialização. Esse explosivo crescimento populacional nos grandes centros urbanos fez com que o processo de ocupação do solo acontecesse de forma desordenada e segregada. Segundo no Brasil, as populações de baixa renda são as mais vulneráveis as enchentes, enxurradas, alagamentos e outros processos devido à ocupação irregular em áreas geologicamente desfavoráveis.

O rápido crescimento da mancha urbana tornou a gestão e o planejamento destas cidades bastante complexo, de maneira que esse crescimento demográfico acelerado resultou no desencadeamento de sérios problemas socioambientais, tais como desmatamento, poluição da água e do ar, ocupação de encostas e margens fluviais, entre outros (SILVA, 2011). Dentre os desastres naturais mais frequentes no Brasil, os eventos de inundações são os que mais causam danos significativos à população. No entanto, o histórico de reportagens de cidades atingidas pelas chuvas ressalta o pouco investimento, tanto em medidas estruturais (obras de infraestrutura) quanto em não estruturais (previsão e planejamento ambiental).

Embora tenha suas origens em processos naturais, as enchentes e inundações podem ser potencializadas pelas atividades humanas, tanto no meio rural, quanto no meio urbano. Tucci e Bertoni (2003) definem inundações como eventos que ocorrem em áreas ribeirinhas no leito maior do rio. Elas são potencializadas pelo processo de urbanização devido à ocupação do solo e transformação desse em superfícies impermeáveis, aumentando a velocidade de escoamento superficial e alterando o ciclo hidrológico, já que diminui a infiltração, além de favorecer a poluição das águas, comprometer a qualidade e diminuir a recarga dos reservatórios subterrâneos.

As enchentes consistem na elevação do nível de água de um rio, acima de sua capacidade natural de escoamento, em períodos da alta precipitação pluviométrica, que pode ou não causar uma inundação. Este processo consiste no extravasamento das águas do leito de escoamento (leito menor) de um corpo hídrico para a planície de inundação (leito maior). Alagamento é um processo que pode ou não ter relação de natureza fluvial. Ele é caracterizado como um acúmulo momentâneo de água em uma área, devido a deficiências nas redes de drenagem, que apresentam dificuldades na capacidade de absorção ou vazão da água (MINISTÉRIO DAS CIDADES/IPT, 2007).

Nas áreas urbanas, as principais consequências desses processos são danos materiais, problemas sanitários (contágio de doenças transmissíveis pela água) e, em casos extremos, perdas de vida. Em ambiente rural, a planície de inundação é ocupada geralmente por uso antrópico relacionado à pecuária e à agricultura, com presença de poucas moradias, fazendo com que os impactos diretos sejam menores do que em meio urbano (TUCCI; BERTONI, 2003).

A partir da relevância do entendimento da dinâmica das inundações e enchentes no espaço urbano, o objetivo geral do estudo é estratificar por Regionais Administrativas de Belo Horizonte-MG, as enchentes e/ou inundações e alagamentos ocorridos entre os anos de 2009/2012 com base nas informações de ocorrência de Inundação da Coordenadoria Municipal de Defesa Civil (COMDEC) e correlacionar ao zoneamento urbanístico da Companhia Urbanizadora de Belo Horizonte (URBEL). Para tanto, tem-se como objetivos 
específicos manipular e tratar os dados da planilha de ocorrência de enchentes, elaborar gráficos para a análise da frequência e recorrência espacial dos registros de ocorrências de inundação e alagamento no município, tabular dados populacionais por padrão de urbanização e espacializar por bairros os registros de ocorrência de inundações, alagamentos, risco de inundações e risco de alagamentos ocorridos em novembro de 2010.

\section{2. ÁREA DE ESTUDO}

Inserida na área de contato entre a Serra do Espinhaço e a Depressão Sanfranciscana, a capital mineira está localizada entre as coordenadas

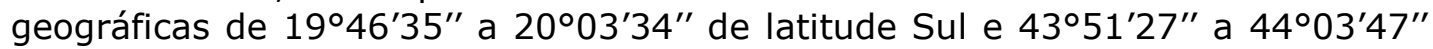
de longitude Oeste. Conforme Nascimento e Aroeira (2006), a maior parte da área urbana se estende por colinas e vales do embasamento cristalino, alguns Bairros da Zona Sul ocupam as encostas da Serra do Curral e os da Zona Norte, ocupam terraços fluviais. Belo Horizonte tem em seu território duas sub-bacias principais, a do Ribeirão do Onça e Ribeirão Arrudas afluentes da Bacia do Rio das Velhas.

Os níveis hipsométricos no município de Belo Horizonte variam de 680m a $1480 \mathrm{~m}$. Estas variações favorecem o aumento do escoamento superficial e, consequentemente, potencializa as enchentes e inundações nas partes mais aplainadas do relevo. A figura 1 mostra que as Regionais Venda Nova, Norte e Nordeste possuem as menores cotas altimétricas, situadas na bacia do Ribeirão do Onça, de grande número de córregos convergentes, constituindo-se as áreas mais aplainadas do município, como também as Regionais Pampulha e a parte norte da Noroeste, que possuem cotas altimétricas entre 780 e $900 \mathrm{~m}$. A Leste, Centro-Sul, Oeste e Barreiro possui diferença hipsométrica de $500 \mathrm{~m}$, sendo que na regional Barreiro essa diferença chega a $780 \mathrm{~m}$, todas elas situadas na bacia do Ribeirão Arrudas.

Planejada para abrigar a nova capital mineira, Belo Horizonte foi projetada para ser uma cidade com parâmetros modernistas, bem diferente da antiga capital Ouro Preto. Inspirada na racionalidade, funcionalidade, higienização e circulação, a cidade era apenas delimitada por uma grande avenida nomeada de Avenida do Contorno, que separava as áreas urbana e suburbana (CARDOSO, 2007). Os traçados retos das ruas eram impostos em uma paisagem de vales, morros e vários cursos d'água.

A história do risco hidrometeórico em Belo Horizonte teve início com a projeção da cidade entre 1894 e 1897. O planejamento inicial desconsiderava as formas naturais de seu sítio e já continha em seu plano suprimir os rios da paisagem urbana. Acreditava-se, de acordo com as teorias higienistas da época, que o melhor a ser feito era implantar a canalização nos córregos para evitar a proliferação de doenças, para aumentar a velocidade de escoamento das águas, evitar a inundação e possibilitar a abertura de vias para o sistema de transporte.

Durante a década de 1950, os processos de urbanização se intensificaram em Belo Horizonte, acarretando diversos problemas devido à expansão difusa sobre o seu território (ASSIS; ABREU, 2010). No projeto original da cidade estimava-se uma população de 200 mil habitantes, a população urbana da capital passou de 350 mil habitantes, na década de 40, para 700 mil habitantes ao longo da década seguinte. Hoje, segundo dados do 
Instituto Brasileiro de Geografia e Estatística (IBGE, 2010), a população de Belo Horizonte é 2.258.096 habitantes, sendo que $19 \%$ encontra-se em áreas de vilas/favelas e conjuntos habitacionais, denominadas de Zona Especial de Interesse Social (ZEIS), definido no Plano Diretor de Belo Horizonte, Lei 7.165, de 1996, identificados pela Companhia Urbanizadora de Belo Horizonte (URBEL), em 2012.

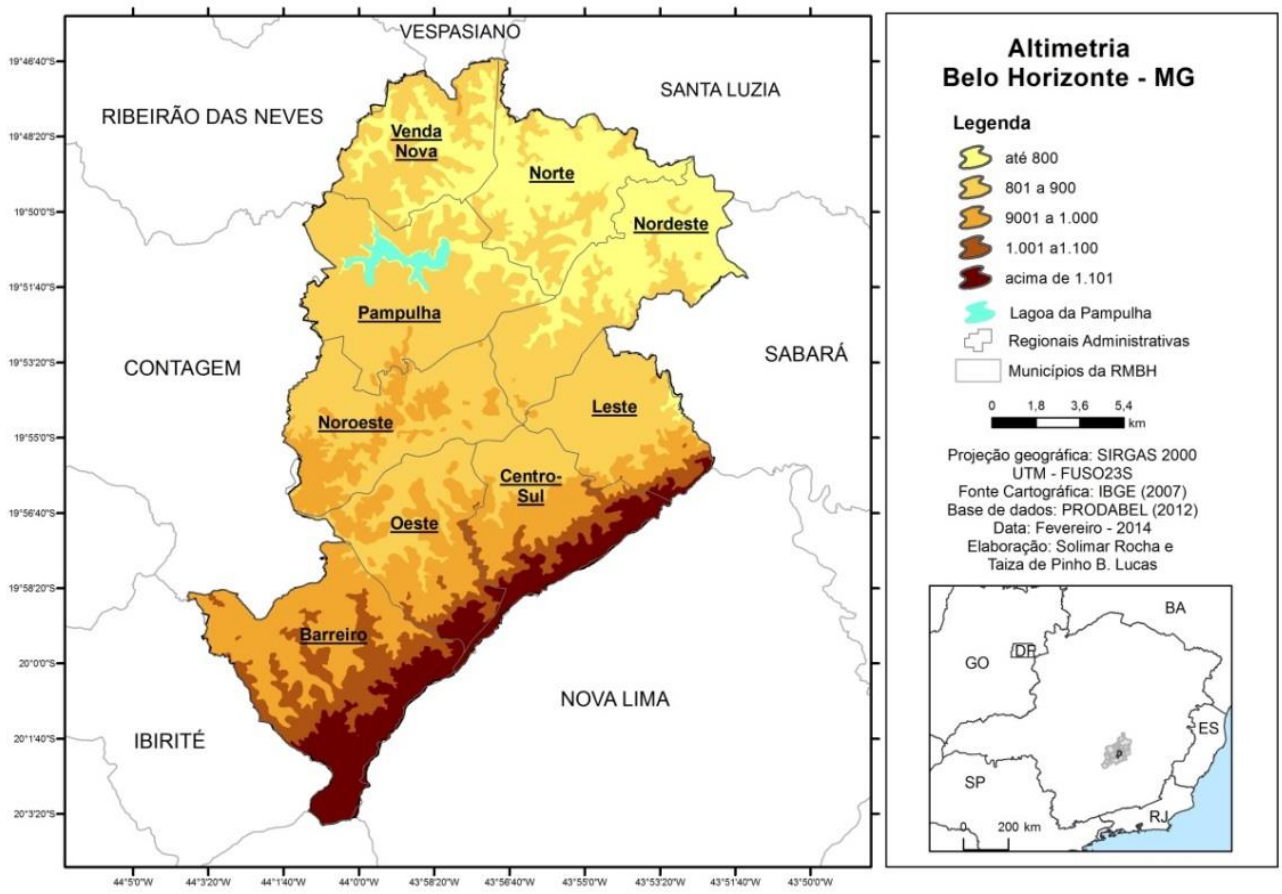

Figura 1 - Mapa Hipsométrico de Belo Horizonte. Fonte de dados: Belo Horizonte (2012). Disponível em: http://gestaocompartilhada.pbh.gov.br. Acesso em 24 de fev. de 2014.

Devido a esse processo de urbanização, a Prefeitura de Belo Horizonte $(\mathrm{PBH})$ teve que expandir a rede de serviços relacionados à drenagem pluvial e ainda hoje se investe no tratamento dos fundos de vale a partir da canalização e ampliação das avenidas sanitárias que, de acordo com Cardoso e Baptista (2009), referem-se à estruturação do sistema viário junto aos fundos de vales. Recentemente, o Estudo de Impacto Ambiental (EIA), realizado no âmbito do Programa de Revitalização Ambiental e Saneamento dos Fundos de Vale e dos Córregos em Leito Natural de Belo Horizonte (DRENURBS), identificou que dos $673 \mathrm{~km}$ de cursos d'água existentes no município, 26\% estão com trechos canalizados, sendo que desses, $6 \%$ são abertos e $20 \%$ fechados (BELO HORIZONTE, 2014).

A figura 2 representa a tipologia desses cursos d'água de Belo Horizonte. Segundo Aroeira (2010), a rede hidrográfica do município compreende uma extensão total de $700 \mathrm{Km}$, sendo que $300 \mathrm{Km}$ estão em áreas de preservação permanente e $400 \mathrm{Km}$ estão inseridos na malha urbana, sendo metade em leito aberto e a outra em leito canalizado, sob as avenidas da capital mineira. 


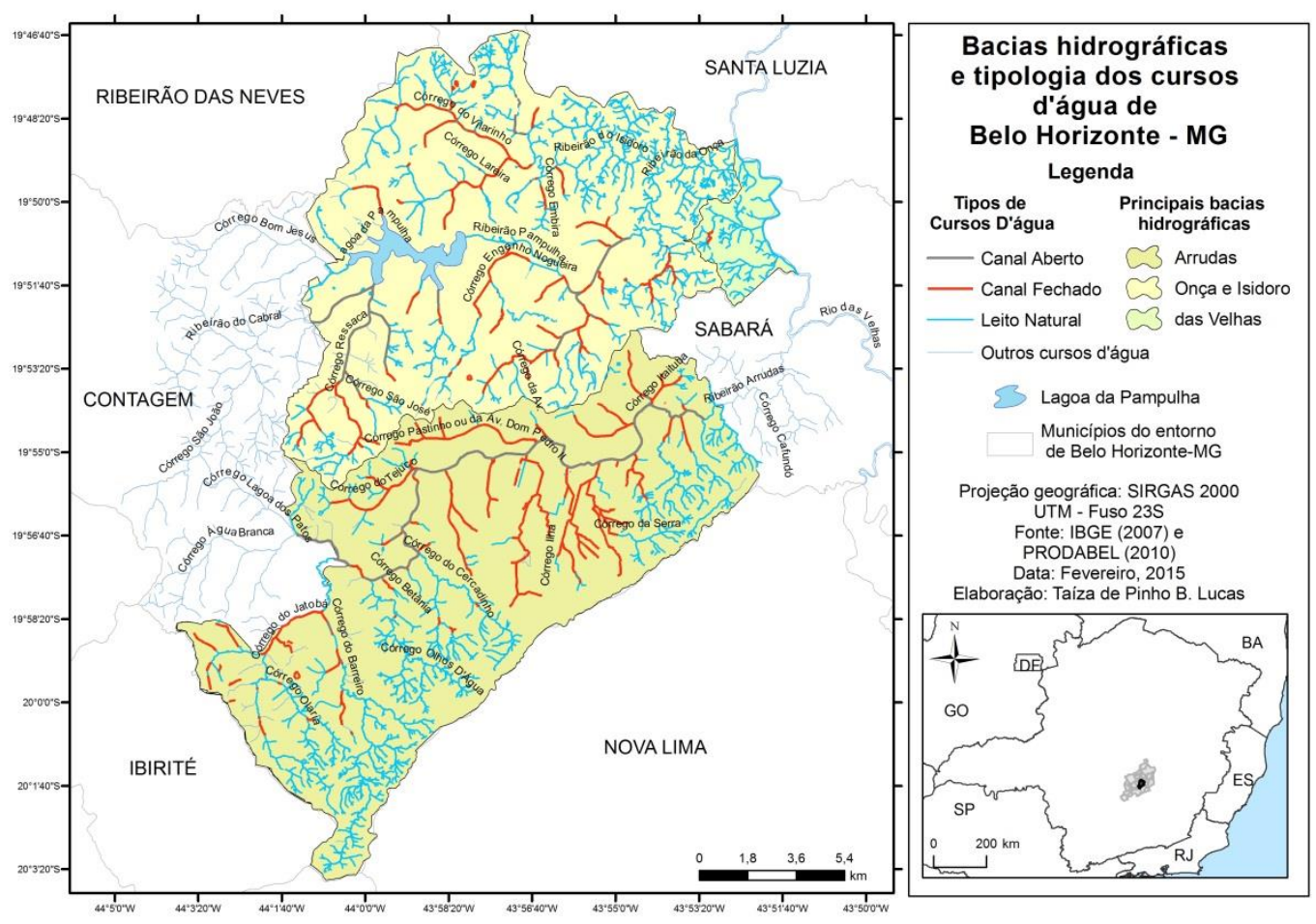

Figura 2 - Mapa das bacias hidrográficas e tipologias dos cursos d'água de Belo Horizonte. Fonte de dados: Belo Horizonte (2010). Disponível em: http://gestaocompartilhada.pbh.gov.br. Acesso em 03 de fev. de 2015.

Apesar de o programa DRENURBS ter como meta principal a revitalização dos cursos d'água, pois Costa, Bontempo e Knauer (2008) ressaltam que o objetivo é "reverter a degradação dos cursos d'água do município que ainda estão em seus leitos naturais e [...] busca inovar no tratamento do saneamento ambiental e de processos participativos de gestão" (COSTA, BONTEMPO, KNAUER. 2008, p.2), verifica-se que a prioridade dos investimentos públicos reverte-se na canalização dos cursos d'água. Segundo dados de Belo Horizonte (2014), já foram investidos R\$210.010.000,00 entre 2010 e 2013, através de orçamento do Governo Municipal e Federal, para o fechamento de 3,7 Km do Ribeirão Arrudas.

Segundo o referido documento, os objetivos das obras são: melhorar as condições de mobilidade, priorizar o transporte coletivo e criar espaços de circulação de pedestres, para tanto foram necessárias obras de recuperação estrutural da laje de fundo, paredes e estrutura de recobrimento do canal e foram criadas novas pistas para o transporte coletivo, acrescidos de elementos paisagísticos, ciclovia e viaduto de transposição da linha férrea. Entretanto, nota-se que as obras de drenagem urbana não são discutidas no âmbito desse processo de canalização.

Para Nascimento e Aroeira (2006), em Belo Horizonte utiliza-se de métodos simples para calcular a dimensão da canalização. Durante o século XX, não houve investimentos no gerenciamento de águas pluviais, assim como no monitoramento do fluxo e qualidade de água. Uma das consequências desse 
mau planejamento do escoamento superficial, que não requer dados observados, foi a subestimação do risco de inundação e seus respectivos efeitos.

Existem relatos que descrevem que desde 1923 a cidade enfrenta essas tragédias. Entre os episódios desastrosos na história da capital estão: $129 \mathrm{~mm}$ no dia 13 de janeiro 1978; $159.9 \mathrm{~mm}$ no dia 3 de janeiro 1979; $238 \mathrm{~mm}$ nos dias 16 e 17 de dezembro de 1984, $150 \mathrm{~mm}$ no dia 16 de dezembro de 2001 e 217,5 mm no dia 16 de janeiro de 2003 (PRUDENTE; REIS, 2009) que causaram grandes enchentes na capital.

Em 12 de dezembro de 1977, 48 horas de chuva (174,2mm), ocasionaram nove mortos, 17 feridos graves, 23 desaparecidos e isolamento da cidade. O ano de 1979 também ficou marcado na memória dos mineiros (figura 3): em 7 de fevereiro, foram abertas as comportas da Lagoa da Pampulha, provocando inundações em Bairros à jusante deixando muitos desabrigados. Em 1987, o Ribeirão Arrudas transbordou, carros foram arrastados, o Parque Municipal Américo René Gianetti, na Regional Centro-Sul, ficou alagado, assim como lojas da Avenida dos Andradas (PRUDENTE; REIS, 2009). Nas imediações do Bairro Padre Eustáquio, as águas do Arrudas chegaram a 100 metros da margem, como ilustram as figuras 3 e 4 .

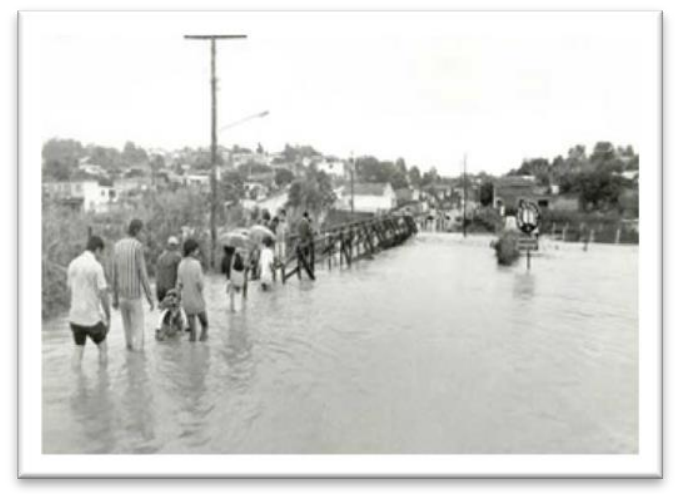

Figura 3 - Córrego do Vilarinho, 1979. Regional Norte de Belo Horizonte. Google Imagens. Acesso em: 12 de maio de 2012

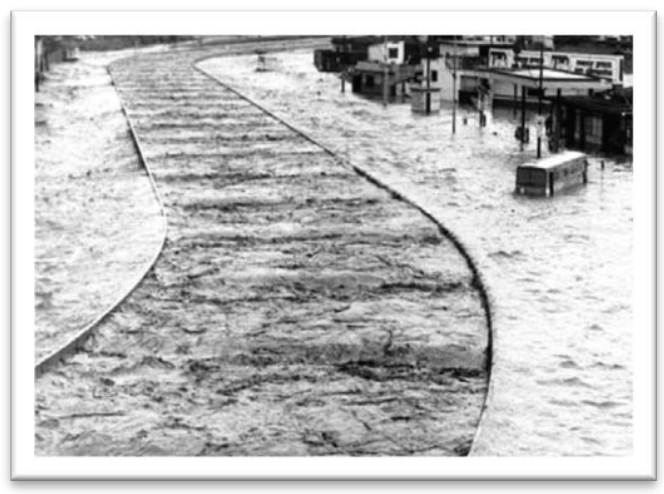

Figura 4 - Ribeirão Arrudas enchente de 1987. Regional Noroeste de Belo Horizonte. Fonte:

Em Belo Horizonte, as chuvas são mais intensas e persistentes no verão, $88 \%$ delas se concentram entre os meses de outubro a março e os $12 \%$ restantes são distribuídos entre os meses de abril a setembro (LUCAS, 2007). No período chuvoso, elas são mais frequentes devido aos fatores climáticos, como eventos meteorológicos de escala regional e sistemas transientes. Por sua localização geográfica, Belo Horizonte sofre influências de fenômenos meteorológicos das latitudes médias e tropicais, isso faz com que a região tenha características de clima de transição (NIMER, 1979).

Segundo Abreu (1998), grande parte da chuva que ocorre em Belo Horizonte nos meses de primavera e verão se deve à atuação da ZCAS (Zona de Convergência do Atlântico Sul) e Sistemas Convectivos de Mesoescala (SCM). A ZCAS é um sistema meteorológico de escala regional que ocorre pela associação entre as LI's (Linhas de Instabilidade Tropical), que se forma na região 
amazônica devido ao intenso aquecimento associado à concentração de umidade e a FPA (Frente Polar Atlântica), um sistema de convergência que origina uma banda de nebulosidade que se orienta no sentido noroeste-sudeste.

Lucas (2007) identificou que as chuvas concentradas e persistentes por mais de três dias seguidos, na Região Metropolitana de Belo Horizonte (RMBH), são originárias desse grande sistema meteorológico de escala sinótica. Prudente e Reis (2009) identificaram que as precipitações acima de $70 \mathrm{~mm}$ em um dia, ou de 50 a $80 \mathrm{~mm}$ acumuladas em até três dias, influenciam a ocorrência de processos naturais perigosos que podem originar impactos socioambientais.

\section{MATERIAIS E MÉTODOS}

Para alcançar os objetivos propostos foram consultados artigos acadêmicos sobre a história do planejamento da capital, estudos das inundações urbanas e riscos hidrometeóricos recorrentes na cidade. Para identificação dos episódios de enchentes/alagamentos foi utilizada a Planilha de registros de inundação da COMDEC no período de outubro 2009 a março de 2012, conforme Belo Horizonte (2012).

A partir da identificação das ocorrências registradas pela COMDEC, a planilha foi manipulada primeiramente por Bairros, localizados a partir das Regionais, depois por tipo de ocorrência. São elas: enchente e/ou inundação, alagamento, temporais ou vendavais, risco de enchente e/ou inundação e risco de alagamento. É necessário salientar que o registro é realizado a partir da notificação da vítima, ou seja, o usuário que aciona a Defesa Civil, o que muitas vezes ocorre muito tempo depois de um imóvel ou via pública serem danificados por eventos hidrometeóricos. Alguns deles relatados pela mídia local não foram registrados pela COMDEC devido à ausência de notificação do usuário.

Segundo a Defesa Civil, as enchentes e/ou inundações são registradas a partir de relatos desses eventos naturais que causam perdas materiais em propriedades privadas e/ou públicas, dentre outros danos, provocados por fortes chuvas. Os casos registrados como risco de inundação são chamados feitos pela população local que solicitam vistoria da Defesa Civil em áreas que já foram inundadas em períodos anteriores. Os alagamentos são ruas, casas e comércios atingidos pelo acúmulo de água em uma determinada área nos períodos de chuvas. Assim, o risco de alagamento são solicitações de vistoria à COMDEC em locais previamente afetados, por medo de novos alagamentos, comumente em períodos chuvosos (BELO HORIZONTE, 2012).

A análise estatística descritiva foi realizada a partir do Excel, pacote Office do Windows 7, para identificação da distribuição de ocorrências por tipo e por Regionais. A partir da técnica de Diagrama de Pareto foi possível analisar a frequência de ocorrências por Regionais Administrativas da Prefeitura de Belo Horizonte.

Os dados de população foram estratificados por Regionais e por padrão de urbanização, em cidade formal e áreas de vilas, favelas e conjuntos habitacionais fornecidos nos atributos do mapeamento dessas ZEIS pela URBEL (2012). A partir das informações desses atributos calculou-se o tamanho dos 
respectivos polígonos, assim como das Regionais Administrativas da Prefeitura de Belo Horizonte $(\mathrm{PBH})$, correspondente à área em $\mathrm{km}^{2}$, no software ArcGIS 9.3 (ESRI, 2003). Os cálculos de densidade demográfica foram manipulados no Excel.

Para geração dos mapas de distribuição espacial das ocorrências registradas pela COMDEC em novembro de 2010, foram agregadas as informações dos dados da planilha à base digital da tabela de código de Bairros da Empresa de Informática e Informação do Município de Belo Horizonte (PRODABEL). A partir da ferramenta de junção de tabelas, Join, do software ArcGIS 9.3, foram importados os registros da camada de dados da COMDEC para a camada de Bairros da PRODABEL.

\section{RESULTADOS E DISCUSSÕES}

Os dados da Planilha de impactos hidrometeóricos da Defesa Civil foram importantes para obtenção da frequência das inundações, enchentes e alagamentos nos quatro anos, 2009-2012, uma vez que eles apresentaram grandes variações no tipo e na localização dessas ocorrências. Nesse período, a maior quantidade de registros de impactos, em Belo Horizonte, ocorreu em 2010 e 2011.

Segundo dados de Belo Horizonte (2012), nesse período foram registrados 1.955 ocorrências. Em 2009 houve 324 notificações de impactos, já em 2010, foram registrados 907, mais do que o dobro do ano anterior. Em 2011, foram registrados 370, em 2012, no mesmo período, foram relatados 354 casos. Os resultados da Planilha de inundação da Coordenadoria da Defesa Civil são apresentados na figura 5, separados por Regional, mostrando o número de ocorrências e a quantidade total de eventos nos quatro anos.

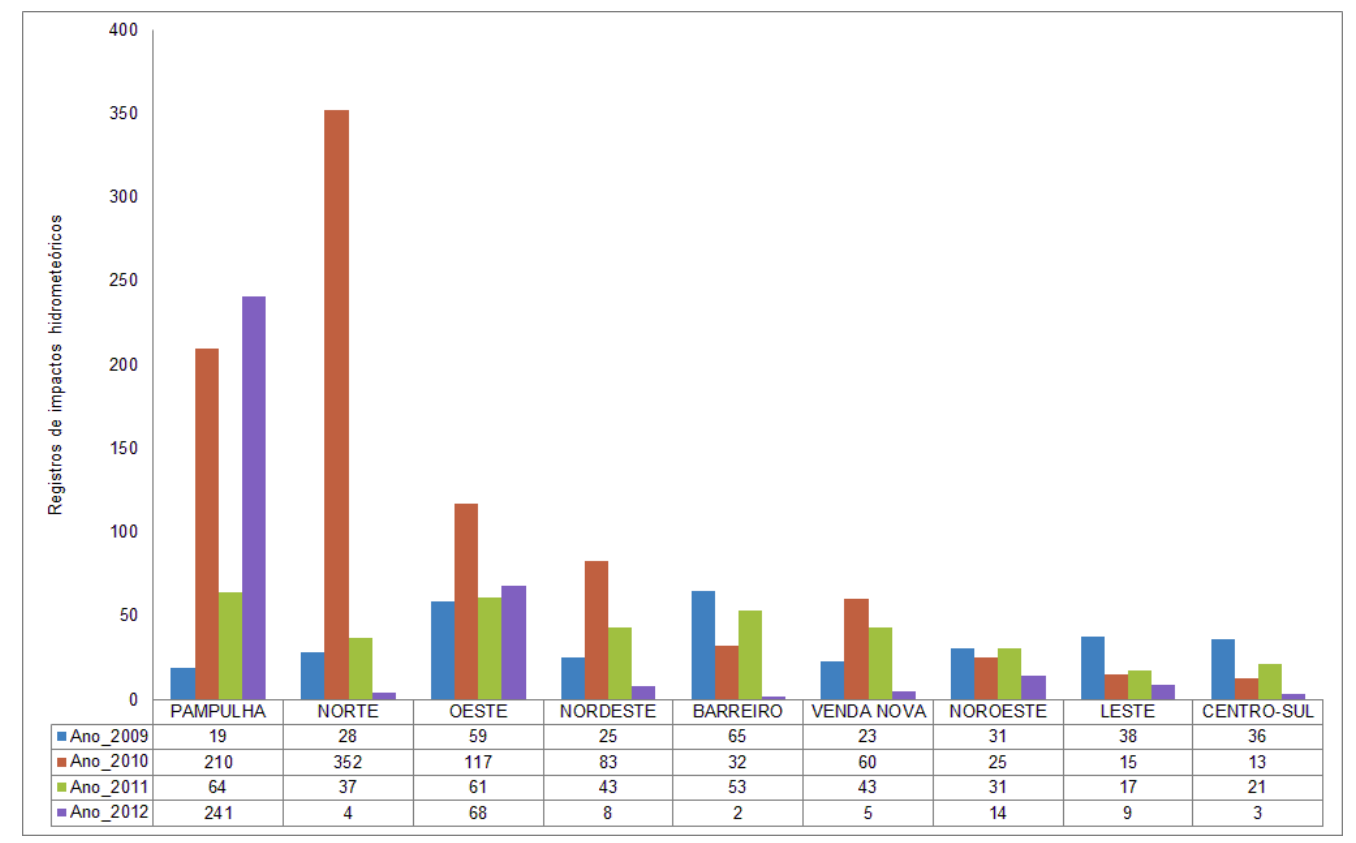

Figura 5 - Número de registros de ocorrências de impactos hidrometeóricos de 2009 a 2012. Fonte de dados: Belo Horizonte (2012). 
De acordo com os resultados apresentados na figura 5, nota-se que as Regionais mais afetadas são: Pampulha e Norte com 955 ocorrências, no total. Essas Regionais estão localizadas nas áreas mais aplainadas do município. Nelas se concentram o maior número de cursos d'água, como os córregos Sarandi, Ressaca, na Regional Pampulha, e os ribeirões do Onça e Isidoro, na Regional Norte. Logo em seguida, aparece a Oeste com 305 registros. Na Nordeste, Barreiro, Venda Nova e Noroeste observam-se entre 100 a 160 ocorrências e nas Regionais Leste e Centro Sul entre 70 a 79, localizadas nas áreas mais elevadas do município.

No período de 2009 a 2012, o número de enchentes e inundações chegou a 821 casos e o de alagamentos ultrapassou 850 ocorrências, registradas pela COMDEC. Em 2009, o número de enchentes e inundações chegou a 101 ocorrências, já em 2010 esse número passou de 600 casos registrados. Conforme dados de Belo Horizonte (2012), no ano de 2010, além das inundações, o número de alagamentos superou o de 2009, chegando a 143 registros. Em 2012 esse número subiu para 327, triplicando o número de ocorrências.

A figura 6 mostra a média de registros de ocorrências de impactos hidrometeóricos, por Regional, entre os anos de 2009 a 2012. A média de ocorrências na Pampulha foi a maior, com 27,4\% dos eventos, em seguida, a Norte com 21,5\% e a terceira, a Oeste com 15,5\%. Juntas elas concentram, aproximadamente, $65 \%$ dos registros. As Regionais Leste e Centro-Sul registraram menos de $5 \%$ da média de ocorrência, esta ocupa o último lugar nesse ranking, com apenas 3,7\%.

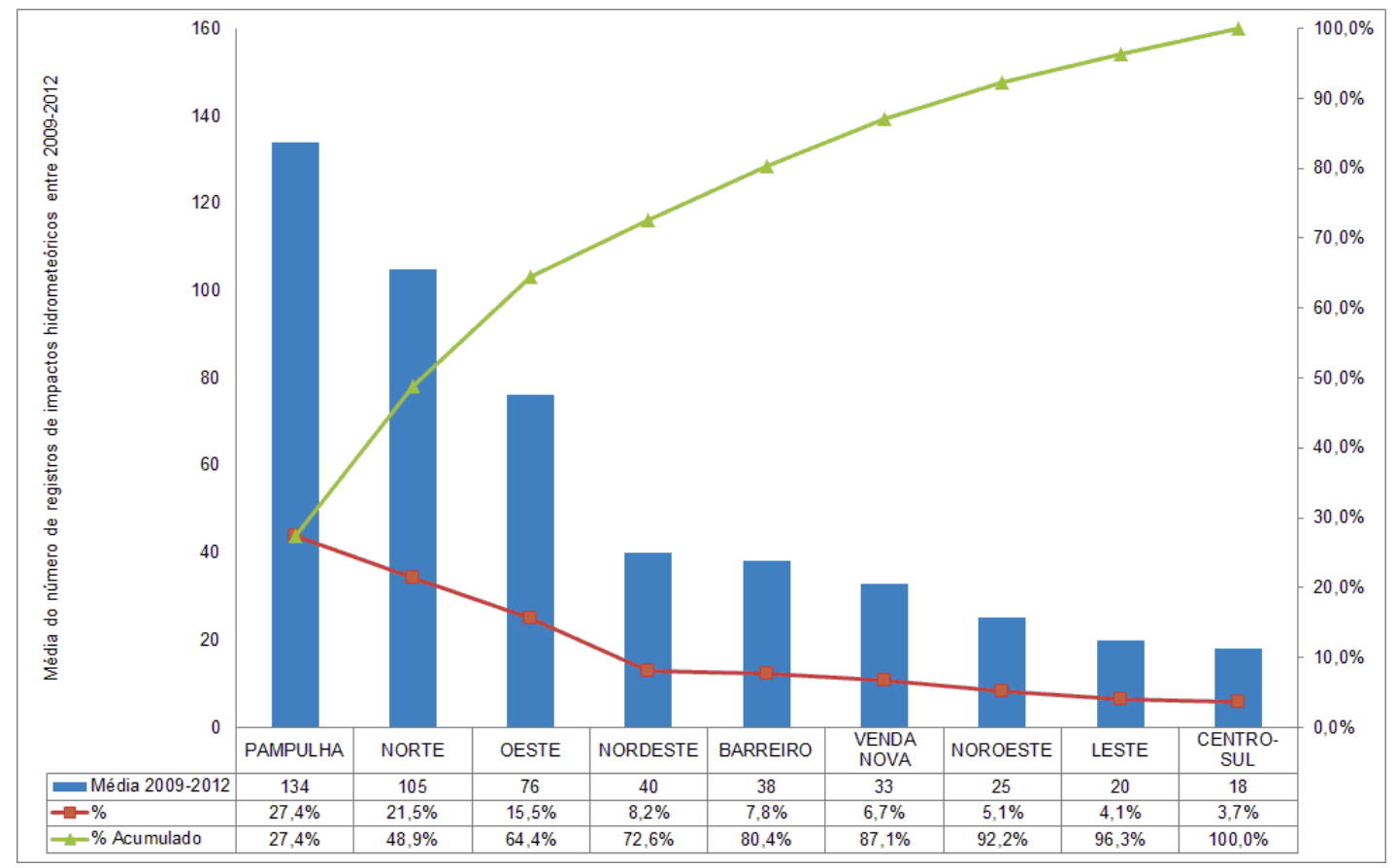

Figura 6 - Média de registros de ocorrências de impactos hidrometeóricos entre 2009 e 2012. Fonte de dados: Belo Horizonte (2012). 
A tabela 1 mostra o número total de registros de ocorrência de enchentes e/ou inundações e alagamentos, por Regionais, separadas pelo tipo de urbanização, categorizados segundo o zoneamento urbano de Belo Horizonte, elaborado pela URBEL (2012). Verifica-se que 38,4\% do total de registros de impactos hidrometeóricos ocorreram nas denominadas ZEIS, que correspondem a $5 \%$ da área territorial do município. As Regionais Norte e Pampulha se diferenciam das demais, não só pelo maior número de registros, mas porque os registros de enchentes e/ou inundações se deram majoritariamente nas áreas de vilas, favelas e conjuntos habitacionais, com $82,9 \%$ e $77,1 \%$ do total. Ao contrário das ocorrências de alagamentos, que ocorreram em grande parte na cidade formal, mais da metade somente nas Regionais Pampulha e Oeste.

Tabela 1 - Total de registros de ocorrências de impactos hidrometeóricos e urbanização

\begin{tabular}{|c|c|c|c|c|c|}
\hline \multirow[b]{3}{*}{ Regional } & \multirow[b]{3}{*}{ Natureza da Ocorrência } & \multicolumn{4}{|c|}{$\mathrm{N}^{\circ}$ registros por Tipo de } \\
\hline & & Número & & ização & \\
\hline & & $\begin{array}{l}\text { Total de } \\
\text { Registros }\end{array}$ & Cidade Formal & $\begin{array}{c}\text { Vilas/Favelas e } \\
\text { Conjuntos } \\
\text { Habitacionais }\end{array}$ & $\begin{array}{c}\text { Vilas/Favelas e } \\
\text { Conjuntos } \\
\text { Habitacionais }\end{array}$ \\
\hline \multirow{2}{*}{ Barreiro } & Enchentes - Inundações & 97 & 76 & 21 & 21,6 \\
\hline & Alagamentos & 115 & 97 & 18 & 15,7 \\
\hline \multirow{2}{*}{ Centro-Sul } & Enchentes - Inundações & 22 & 19 & 3 & 13,6 \\
\hline & Alagamentos & 58 & 42 & 16 & 27,6 \\
\hline \multirow{2}{*}{ Leste } & Enchentes - Inundações & 32 & 20 & 12 & 37,5 \\
\hline & Alagamentos & 99 & 42 & 57 & 57,6 \\
\hline \multirow{2}{*}{ Nordeste } & Enchentes - Inundações & 105 & 64 & 41 & 39,0 \\
\hline & Alagamentos & 100 & 72 & 28 & 28,0 \\
\hline \multirow{2}{*}{ Noroeste } & Enchentes - Inundações & 41 & 31 & 10 & 24,4 \\
\hline & Alagamentos & 78 & 62 & 16 & 20,5 \\
\hline \multirow{2}{*}{ Norte } & Enchentes - Inundações & 409 & 70 & 339 & 82,9 \\
\hline & Alagamentos & 102 & 35 & 67 & 65,7 \\
\hline \multirow{2}{*}{ Oeste } & Enchentes - Inundações & 144 & 105 & 39 & 27,1 \\
\hline & Alagamentos & 372 & 332 & 40 & 10,8 \\
\hline \multirow{2}{*}{ Pampulha } & Enchentes - Inundações & 214 & 49 & 165 & 77,1 \\
\hline & Alagamentos & 393 & 357 & 36 & 9,2 \\
\hline \multirow{2}{*}{ Venda Nova } & Enchentes - Inundações & 52 & 29 & 23 & 44,2 \\
\hline & Alagamentos & 103 & 59 & 44 & 42,7 \\
\hline Total & & 2536 & 1561 & 975 & 38,4 \\
\hline
\end{tabular}

Fonte de dados: COMDEC e URBEL (2012).

A dinâmica populacional e valoração do uso do solo são bem diversas ao comparar as Regionais Pampulha e Norte. A partir da tabela 2, verifica-se que apesar da Norte constituir-se de menor número ZEIS, elas correspondem a $7 \%$ da área territorial da Regional, enquanto na Pampulha elas ocupam 1,7\%. A Norte é a segunda com maior percentual de população residente nestas áreas, em relação à população total da Regional, atrás somente da Leste, que assim como a Norte tiveram maior número de registros de alagamentos nessas ZEIS 
(tabela 1). Observa-se que na Pampulha encontra-se o menor percentual dessa população, com a menor densidade demográfica tanto da população total como residente em vilas, favelas e conjuntos habitacionais, segundo dados da URBEL (2012).

Tabela 2 - Número de ZEIS, área e dados populacionais por Regionais

\begin{tabular}{|c|c|c|c|c|c|c|c|c|c|}
\hline Regional & $\begin{array}{l}N^{0} \text { de } \\
\text { ZEIS }\end{array}$ & $\begin{array}{c}\text { Área das } \\
\text { ZEIS } \\
\left(\mathrm{Km}^{2}\right)\end{array}$ & $\begin{array}{l}\text { Área } \\
\text { Total } \\
\left(\mathrm{Km}^{2}\right)\end{array}$ & $\begin{array}{l}\% \text { área } \\
\text { de ZEIS }\end{array}$ & $\begin{array}{l}\text { População } \\
\text { Total das } \\
\text { ZEIS }\end{array}$ & $\begin{array}{c}\text { População } \\
\text { Total }\end{array}$ & $\begin{array}{c}\% \\
\text { População } \\
\text { de ZEIS }\end{array}$ & $\begin{array}{c}\text { Densidade } \\
\text { Demográfica da } \\
\text { População de } \\
\text { ZEIS } \\
\end{array}$ & $\begin{array}{c}\text { Densidade } \\
\text { Demográfica da } \\
\text { População } \\
\text { Total }\end{array}$ \\
\hline Barreiro & 32 & 2,66 & 53,5 & 5,0 & 56.316 & 282.552 & 19,9 & $21.171,4$ & $5.285,3$ \\
\hline Centro-Sul & 19 & 2,39 & 31,7 & 7,5 & 71.894 & 283.776 & 25,3 & $30.081,2$ & $8.943,5$ \\
\hline Leste & 23 & 2,38 & 27,9 & 8,5 & 64.740 & 238.539 & 27,1 & $27.201,7$ & $8.549,8$ \\
\hline Nordeste & 30 & 1,53 & 39,3 & 3,9 & 39.340 & 290.353 & 13,5 & $25.712,4$ & $7.382,5$ \\
\hline Noroeste & 18 & 0,87 & 30,1 & 2,9 & 34.280 & 268.038 & 12,8 & $39.402,3$ & $8.910,8$ \\
\hline Norte & 16 & 2,29 & 32,6 & 7,0 & 54.569 & 212.055 & 25,7 & $23.829,3$ & $6.512,7$ \\
\hline Oeste & 36 & 2,5 & 35,9 & 7,0 & 77.744 & 308.549 & 25,2 & $31.097,6$ & $8.587,5$ \\
\hline Pampulha & 21 & 0,86 & 51,0 & 1,7 & 18.870 & 226.110 & 8,3 & $21.941,9$ & $4.430,1$ \\
\hline Venda Nova & 20 & 0,97 & 29,2 & 3,3 & 33.552 & 265.179 & 12,7 & $34.589,7$ & $9.093,9$ \\
\hline Total & 215 & 16,45 & 331,2 & 5,0 & 451.305 & 2.375 .151 & 19,0 & & \\
\hline
\end{tabular}

Fonte de dados: COMDEC e URBEL (2012).

A Regional Oeste é a que possui maior número de ZEIS, assim como a Norte, ocupam $7 \%$ do território, ela também possui maior número de população total, e, por conseguinte, maior população residente nessas áreas. A segunda Regional com maior número de ZEIS é o Barreiro, elas totalizam a maior área, o que não corresponde ao maior percentual em relação à área total em função do maior território da Regional, como pode ser observado pelo menor valor da densidade demográfica da população de ZEIS. Grande parte desta Regional é destinada à preservação ambiental em função da alta declividade do terreno, dado os desníveis apresentados na figura 1 , o que torna a falta de planejamento e gerenciamento do uso do solo urbano propenso a essas ocupações, como historicamente ocorreu com as encostas da Serra do Curral nas Regionais Leste e Centro-Sul, que podem ser observadas pelo número de população residente nas ZEIS, assim como pelo percentual do tamanho dessas áreas em relação ao território da Regional.

As diferenças de registros de impactos entre as Regionais de Belo Horizonte refletem as características físicas das bacias do Ribeirão Arrudas e do Onça, aquelas de maior frequência de registro pertencem a esta última. Segundo Reis (2011), a bacia do Ribeirão do Onça apresenta rede de drenagem próxima ao dendrítico, a partir da classificação fluvial de Christofoletti (1980), como pode ser observado ao comparar as figuras 7 e 8 , com cursos d'água em padrão fluvial meandrante de baixa sinuosidade, caracterizando-se como uma bacia circular a ramificada. A figura 7 permite observar que são áreas de relevo mais aplainados, comparados à bacia do Arrudas, com altitudes que variam entre 678 a $964 \mathrm{~m}$. 


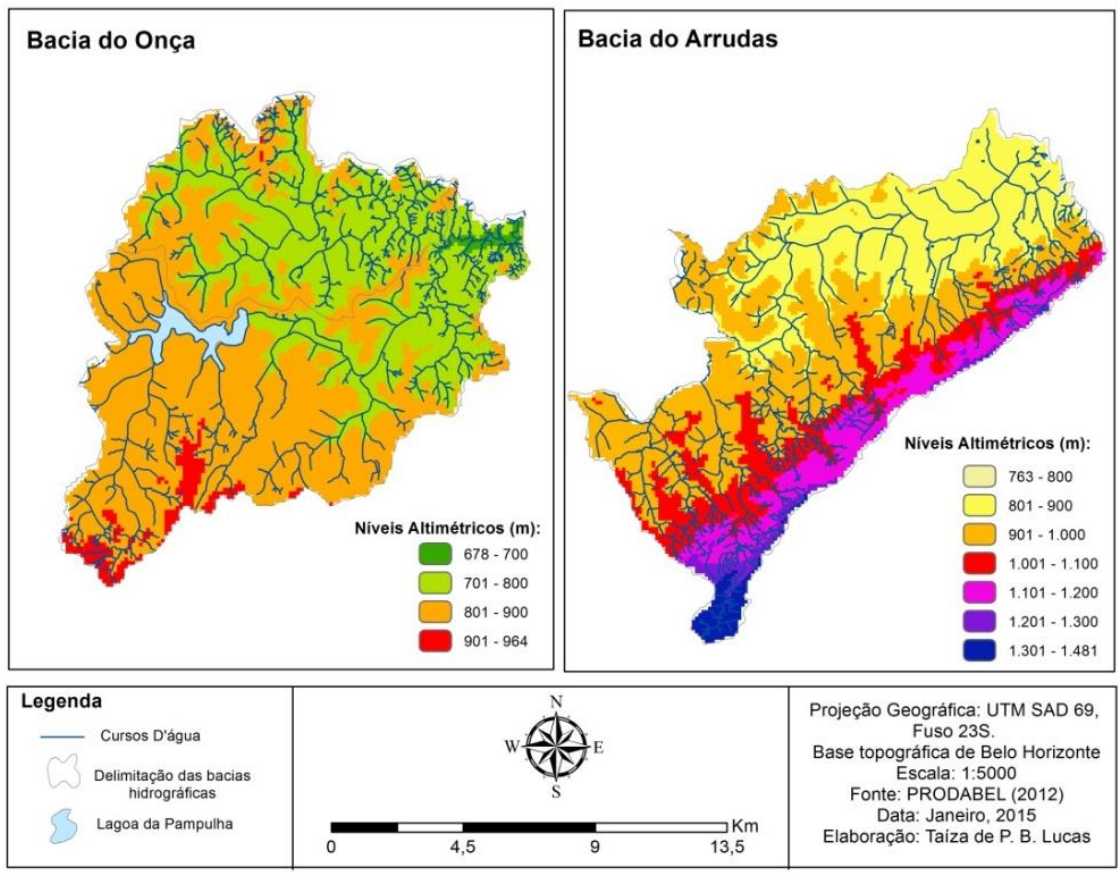

Figura 7 - Mapa Hipsométrico das bacias do Arrudas e Onça em Belo Horizonte-MG. Fonte de dados: Belo Horizonte (2012). Disponível em: http://gestaocompartilhada.pbh.gov.br. Acesso em 24 de fev. de 2014.

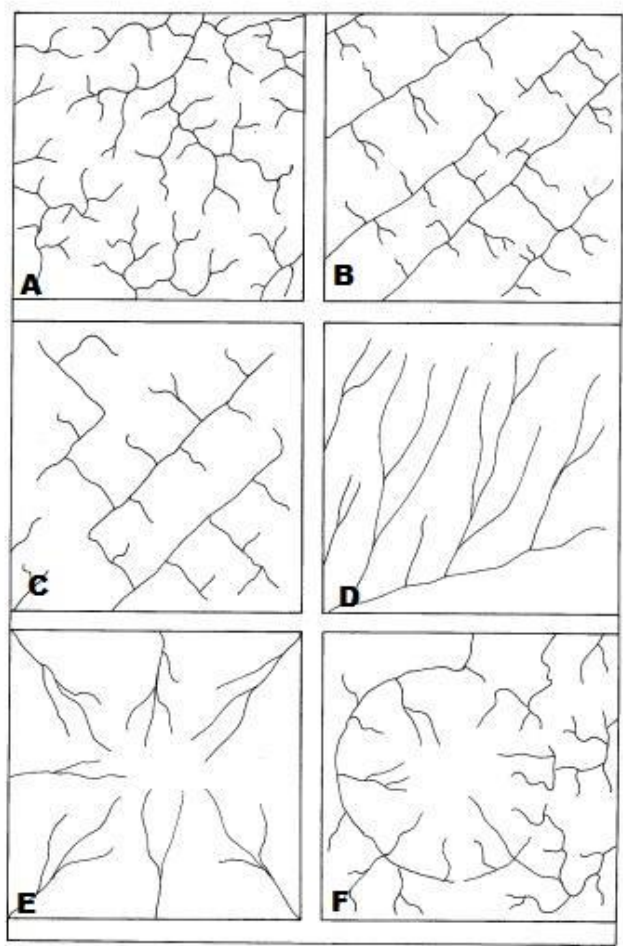

Figura 8 - Padrões de drenagem. A) Dentrítico; B) Treliça; C) Retangular; D) Paralela; E) Radial e F) Anelar. Fonte: Christofoletti (1980). 
A bacia do Arrudas caracteriza-se por um padrão de drenagem paralela e forma elíptica a ramificada, em praticamente, toda extensão da margem direita, perpendicular à crista da Serra do Curral. Ela é formada por um conjunto de sub-bacias alongadas que convergem para o mesmo curso principal (REIS, 2011). Segundo a autora, a direção preferencial do escoamento superficial é condicionada pela geologia, as maiores elevações (figura 7) e a declividade, que favorecem o escoamento superficial e menor tempo de concentração até a parte central da bacia. Essas características influenciam menores ocorrências nas Regionais Barreiro, Centro-Sul e Leste da capital mineira, em que predominam outros impactos geológicos ocasionados pela saturação do solo.

\section{A espacialização das enchentes e/ou inundações e alagamentos do mês de novembro de 2010}

As figuras 9, 10, 11 e 12 representam a espacialização dos eventos de risco de enchentes e/ou inundações, enchentes e/ou inundações, risco de alagamentos e de alagamento no mês de novembro do ano de 2010, no município de Belo Horizonte. A partir da figura 5, verificou-se que no ano de 2010 ocorreram 907 registros de impactos hidrometeóricos, enquanto em 2009 foram registrados 324, em 2011, 370 e em 2012, 354. Desse total de 907 em 2010, 605 ocorreram só no mês de novembro de 2010. As figuras permitem visualizar a distribuição das ocorrências desses impactos por Bairros e suas respectivas Regionais. 


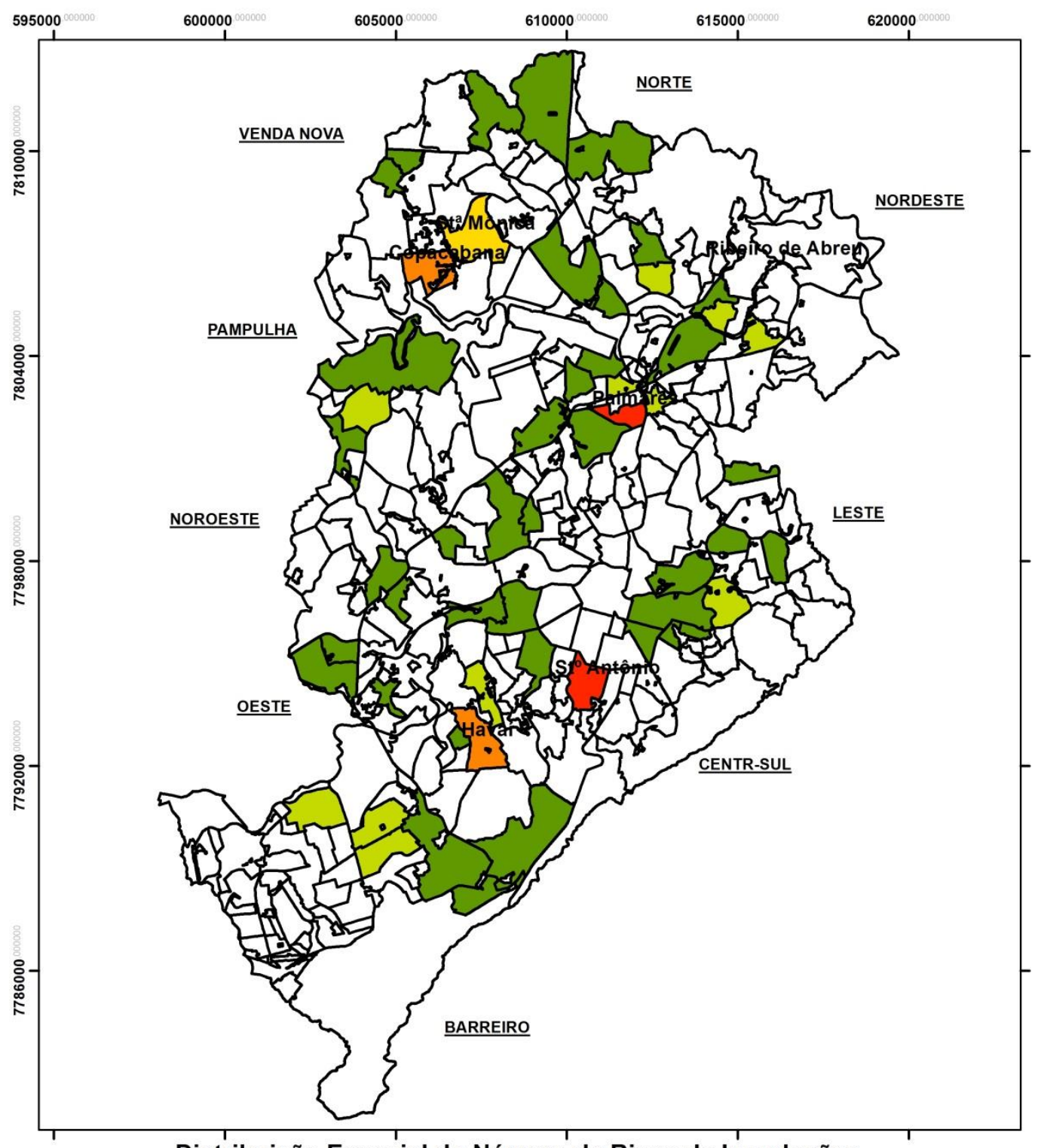

Distribuição Espacial do Número de Risco de Inundações por Bairros de Belo Horizonte em Novembro de 2010

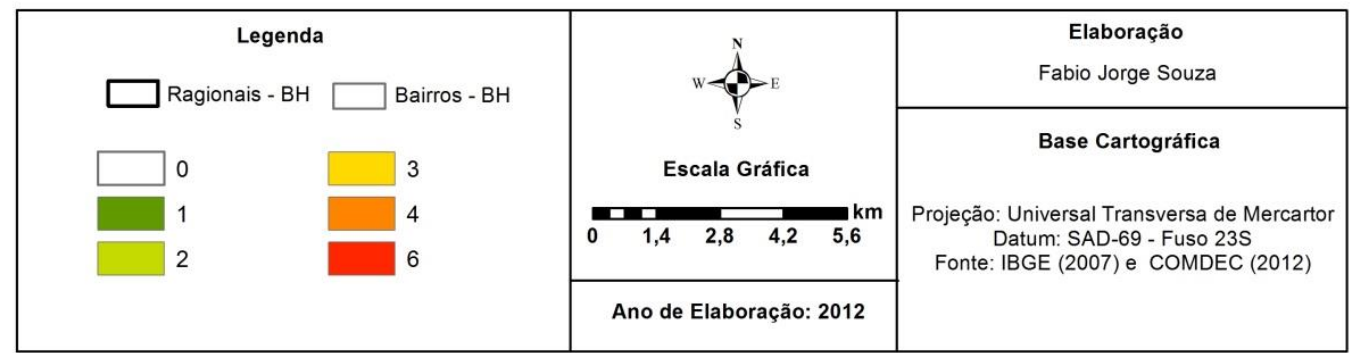

Figura 9 - Distribuição do número de solicitações de vistorias sobre o Risco de Inundações em 2010. Fonte de dados: Belo Horizonte (2012). 


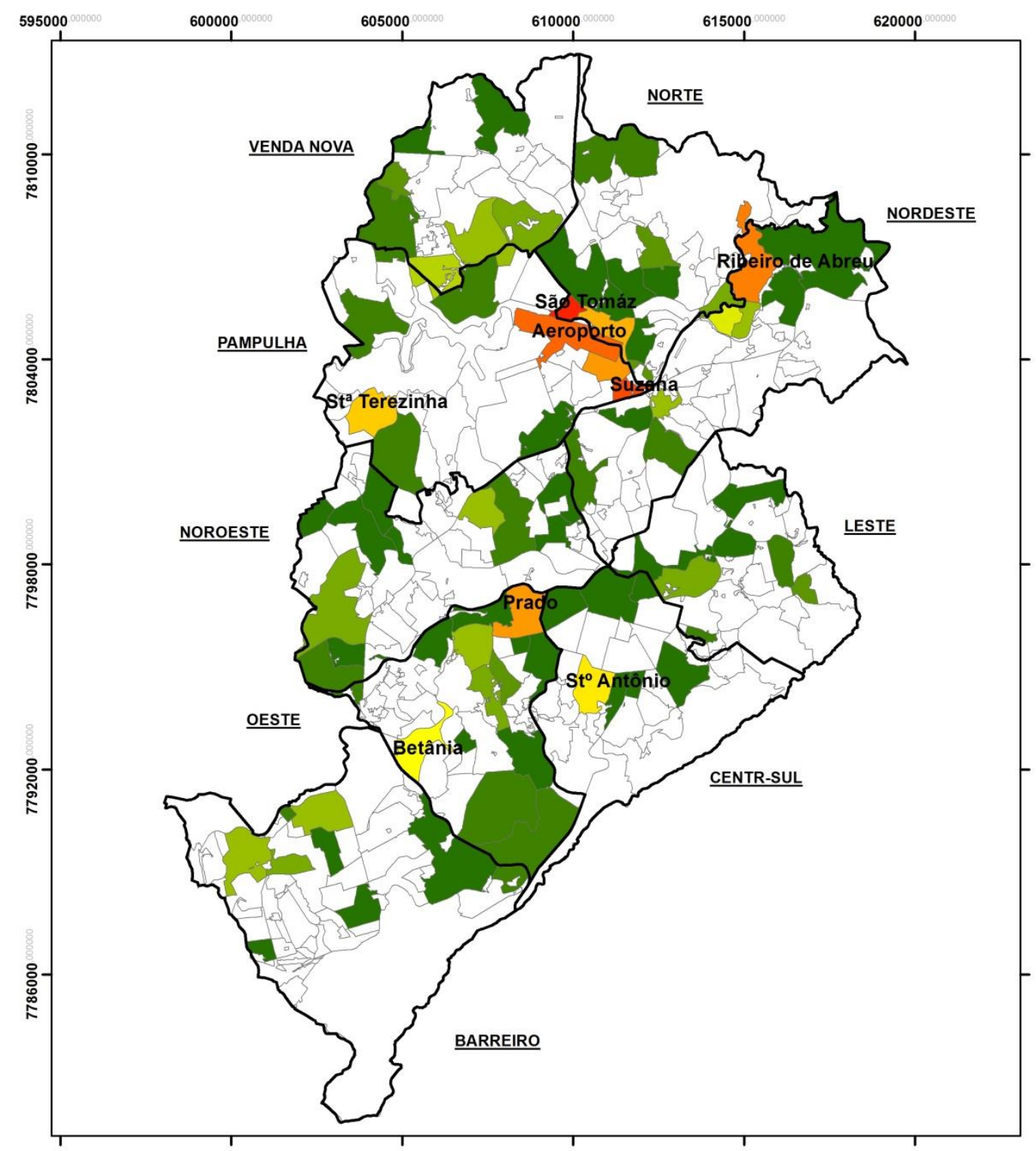

Distribuição Espacial do Número de Enchentes e/ou Inundações por Bairros de Belo Horizonte em Novembro de 2010

\begin{tabular}{|c|c|c|c|c|c|}
\hline \multicolumn{8}{|c|}{ Legenda } & & Elaboração \\
Fabio Jorge Souza
\end{tabular}

Figura 10 - Distribuição do número de ocorrências de Enchentes e/ou Inundações em 2010. Fonte de dados: Belo Horizonte (2012). 


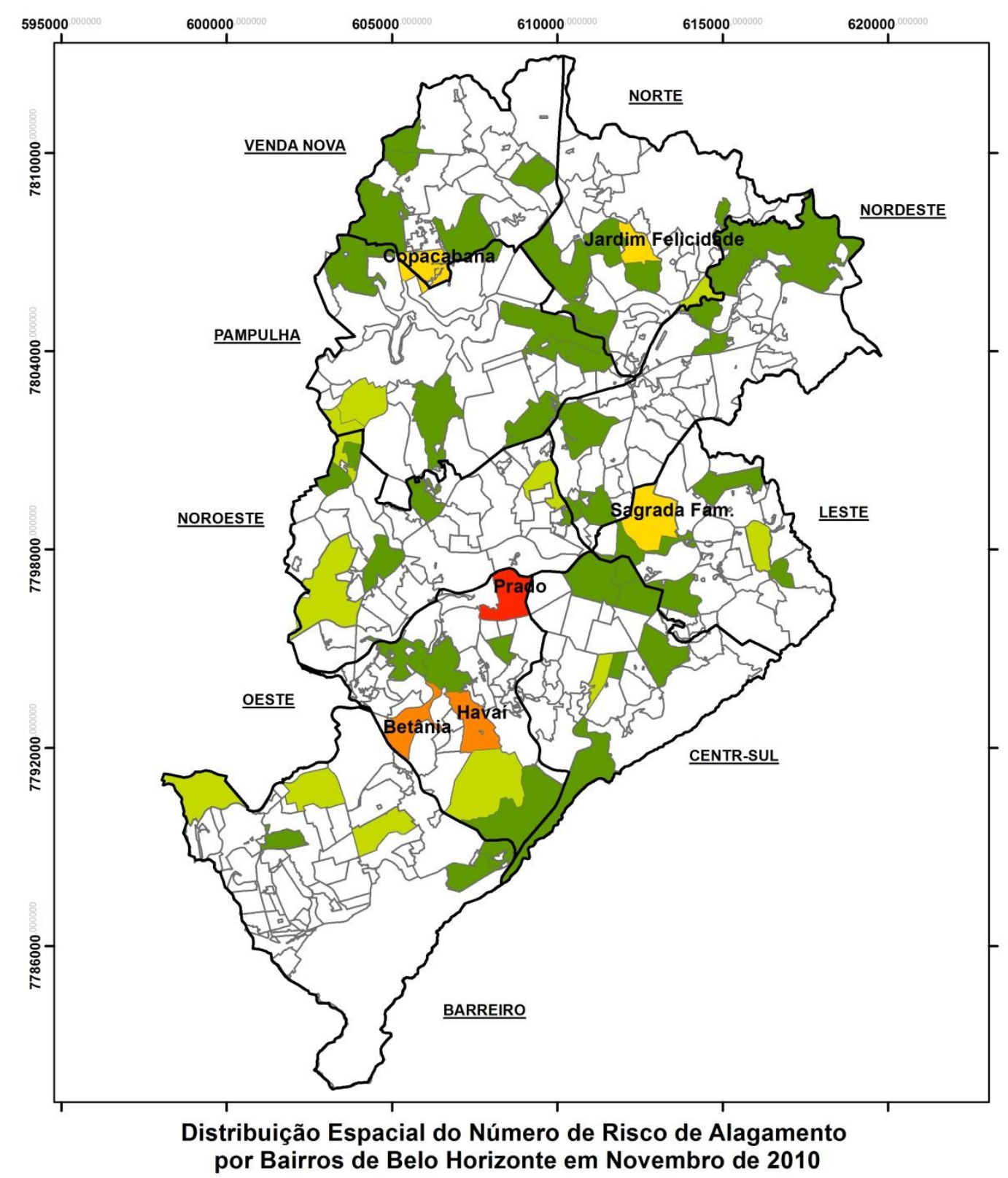

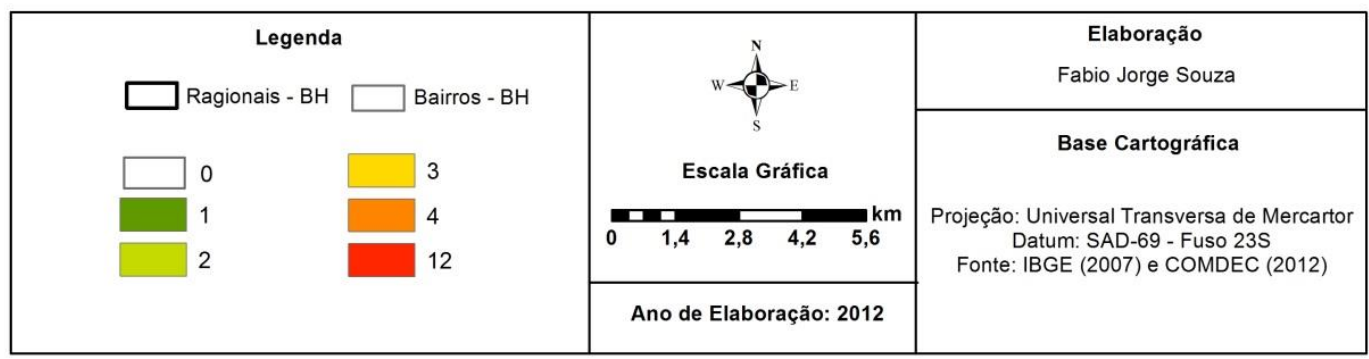

Figura 11 - Distribuição do número de solicitações de vistoria sobre Risco de Alagamentos em 2010. Fonte de dados: Belo Horizonte (2012). 

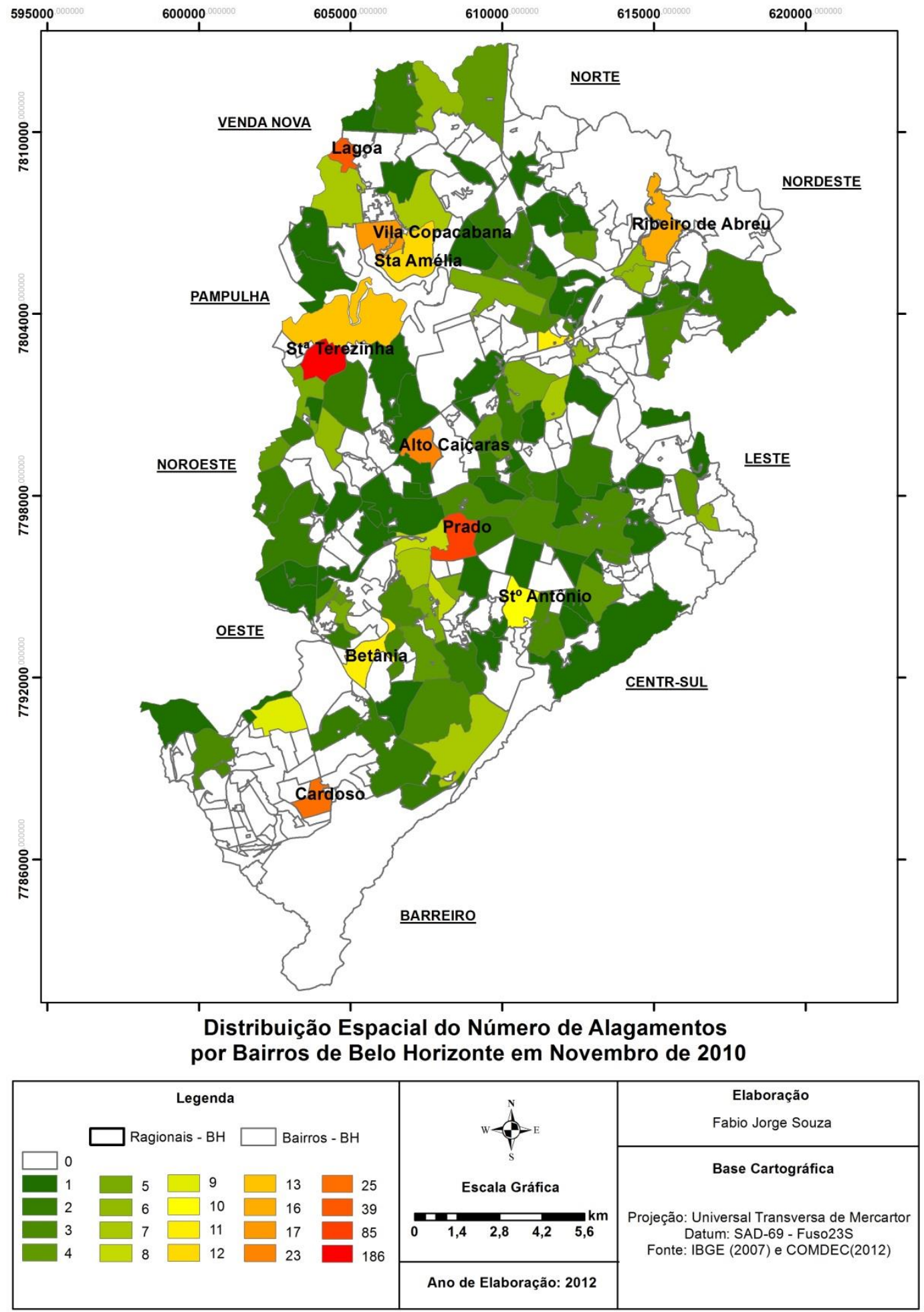

Figura 12 - Distribuição do número de ocorrências de Alagamentos em 2010. Fonte de dados: Belo Horizonte (2012). 
A figura 9 representa as ocorrências de risco de inundações recebidas pela COMDEC. Os bairros com maior número de registros são: Havaí, Santo Antônio, Palmares, Santa Mônica e Copacabana, com uma variabilidade de três a seis chamados. A figura 10 representa as ocorrências de enchentes e/ou inundações, observa-se que há um aumento das solicitações em se tratando do fato em si. A maior parte dos bairros inundados se encontra nas Regionais Oeste, Noroeste e Pampulha, havendo maior número de ocorrência nos bairros Prado, Betânia, Santa Terezinha, Suzana, Aeroporto, São Bernardo e Vila São Tomáz, no último chegando a 158 casos registrados, o que explica o percentual de $77,1 \%$ dos registros de ocorrências de enchentes e/ou inundações nas áreas de ZEIS, na Regional Pampulha, visto na tabela 1.

As Regionais de Venda Nova, Nordeste e Norte da capital também são bastante afetadas, só no Bairro Ribeiro de Abreu foram 22 ocorrências. Outras áreas, como a Regional Barreiro, Leste e Centro Sul apresentaram um número menor de casos, chegando a uma ou duas ocorrências.

As figuras 11 e 12 representam o risco de alagamento e as ocorrências de alagamento registradas pela COMDEC. Nota-se que a figura 11 é semelhante à figura 9, as áreas com risco de alagamento são menores que as áreas de ocorrência do fato em si, ao comparar com os registros de alagamentos ocorridos em novembro de 2010, espacializados na figura 12 .

O número de solicitações de vistoria da Defesa Civil é maior nas Regionais Pampulha, Noroeste e Oeste. Devido ao risco eminente de alagamento, somaram um total de 27 bairros susceptíveis em novembro de 2010. No bairro Betânia, localizado na Regional Oeste, foram relatadas quatro ocorrências de possível alagamento. Dentre outros, estão o Havaí, Copacabana, Jardim Felicidade e Prado, com o número de solicitações registradas de três a doze chamados, como mostra a figura 11.

As ocorrências de alagamentos registraram o maior número de eventos hidrometeóricos em Belo Horizonte, em novembro de 2010, quando esse tipo de impacto foi registrado em praticamente todas as Regionais. O Barreiro apresentou o menor número de ocorrências devido ao elevado percentual de inclinação do terreno em função da complexidade do relevo, que favorece a formação de enxurradas, mas não de alagamentos, como se observa ao comparar as figuras 7 e 12. Por outro lado, no Bairro Santa Terezinha, Regional Pampulha, foram registrados 186 casos de alagamento. Nessa região da Depressão Belorizontina, outros sete bairros sofreram com o mesmo tipo de impacto. Nas Regionais Noroeste, Oeste e Centro Sul aproximadamente $70 \%$ dos bairros foram afetados. Na capital mineira, os bairros que tiveram o maior número de ocorrências foram: Lagoa, Ribeiro de Abreu, Alto Caiçaras, Prado, Betânia, Santo Antônio e Cardoso.

\section{CONSIDERAÇÕES FINAIS}

O estudo apresenta a distribuição de impactos ou risco de eventos hidrometeóricos por meio de gráficos e mapeamentos, a partir de dados registrados pela COMDEC. Conforme os dados apresentados, todas as Regionais administrativas de Belo Horizonte - MG apresentam pontos de alagamento ou 
inundação. As Regionais Pampulha, Norte e Oeste concentram o maior número de ocorrências registradas pela COMDEC entre 2009 - 2012. Essas Regionais somam $64 \%$ dos casos, sendo que na primeira ocorreram $27 \%$. A espacialização das enchentes e alagamentos de 2010 apontou que mais de $80 \%$ da área de Belo Horizonte sofre com processos hidrológicos.

Ao analisar os dados das tabelas 1 e 2 e as figuras 9 a 12 entende-se que as populações de vilas/favelas e conjuntos habitacionais na bacia do Onça são mais vulneráveis à ocorrência de enchentes e/ou inundações. As características hidrológicas da bacia, por apresentar-se mais arredondada, com córregos sinuosos em terrenos mais aplainados potencializam o risco desses impactos hidrometeóricos, particularmente à população ribeirinha situada nas Regionais Norte, devido ao alto percentual de áreas ocupadas por essa população, a Nordeste, em função do número das ZEIS, Venda Nova, pela elevada densidade demográfica dessa população, como da população total, e da Pampulha que apesar de menor número de pessoas nessas áreas, ainda assim elas são mais vulneráveis devido à frequência de impactos.

O tapamento dos córregos e rios de forma parcial resolve o problema de inundação localmente, mas causa problemas à jusante devido ao aumento de escoamento e/ou à montante em função da ressurgência, muitas vezes ocasionada por estrangulamentos nos córregos canalizados fechados, por excesso de lixo, etc, o que gera alagamentos em áreas não diretamente ligadas aos cursos d'água, mas ao sistema de drenagem formado pelas galerias de água pluvial. Dada essa complexidade do sistema hidrológico urbano, em quase todas as Regionais, exceto nas Regionais Leste e Norte, os alagamentos ocorreram majoritariamente nas áreas denominadas de Cidade Formal, pela URBEL (2012). A figura 12 mostrou que ela é recorrente em todo município, particularmente na Pampulha e na Regional Oeste, onde se concentra o maior número de pessoas por Regional, na capital mineira.

A Regional Pampulha, onde encontram-se grandes equipamentos urbanísticos e turísticos da cidade, tem uma rede de drenagem densa com muitos trechos canalizados e outros abertos, o que gera uma série de impactos hidrometeóricos pontuais e à jusante do Córrego do Onça. Esta Regional requer normatizações de uso e ocupação mais rígidas e políticas públicas bem definidas para diminuir a vulnerabilidade ambiental da população em geral, o que demonstra a necessidade de planejamento de uso do solo e sistema de drenagem integrado que considere a fragilidade ambiental da área.

A gestão do uso do solo e das águas deve considerar não só essa fragilidade e particularidade de cada Regional, mas a sua repercussão nas demais. O complexo sistema de drenagem e ocupação dos leitos dos córregos da Regional Pampulha desencadeia impactos na Regional Nordeste, particularmente no Bairro Ribeiro de Abreu, que requer políticas públicas urbanísticas e sociais devido ao tipo de ocupação precária da área e, comumente, registra um elevado número de ocorrências de inundações. 0 mesmo ocorre com o intenso uso do solo e ocupação da Regional Venda Nova, verificada pelos altos valores da densidade demográfica, e os impactos à população ribeirinha da Regional Norte.

Portanto, é de extrema relevância a revisão do sistema de drenagem e captação da água de chuva através de um planejamento que considere aspectos 
estruturais e não-estruturais pelos gestores municipais, através de politicas públicas eficazes de preservação dos leitos dos rios e qualidade das suas águas.

Agradecimentos: À Coordenadoria de Defesa Civil da Prefeitura Municipal de Belo Horizonte, pelo fornecimento dos dados de impactos hidrometeorológicos ocorridos no período de estudo.

\section{REFERÊNCIAS BIBLIOGRÁFICAS}

ABREU, M. L. de. Climatologia da estação chuvosa de Minas Gerais: de Nimer (1977) a Zona de Convergência do Atlântico Sul. Geonomos, Belo Horizonte, v. 2, n. 6, p.17-22, dez. 1998.

AROEIRA, R. de M. Programa Drenurbs: Prefeitura de Belo Horizonte - Brasil. In: MACHADO, A. T. G. da M.; LISBOA, A. H.; ALVES, C. B. M.; LOPES, D. A.; GOULART, E. M. A.; LEITE, F. A. ; POLIGNANO, M. V. Revitalização de rios no mundo:América, Europa e Ásia. 1 ed. Belo Horizonte: Instituto Guaicuy Projeto Manuelzão/Universidade Federal de Minas Gerais, 2010.p.221-240.

ASSIS, W. L. de; ABREU, M. L. de. Mudanças climáticas locais no município de Belo Horizonte ao longo do século XX. In: HOGAN, Daniel Joseph; MARANDOLA JUNIOR, Eduardo. População e mudança climática: dimensões humanas das mudanças ambientais globais. Campinas: Nepo-Unicamp, 2009. p. 249275.

BELO HORIZONTE. Companhia Urbanizadora de Belo Horizonte. Mapeamento dos assentamentos existentes em Belo Horizonte. 2012. Disponível em: http://gestaocompartilhada.pbh.gov.br/mapas-e-estatisticas/mapas-

estaticos?term_node_tid_depth=All\&area $=692 \&$ field_formato_tid $=695$. Acesso em 09 fev. 2015.

BELO HORIZONTE. Coordenadoria de Defesa Civil do Município de Belo Horizonte. Prefeitura Municipal de Belo Horizonte. Planilha de ocorrência de sinistros em função de impactos hidrometeorológicos de 2009 a 2012. 2012. Disponível em: http://portalpbh.pbh.gov.br/pbh/ecp/comunidade. Acesso em: 25 jun. 2012.

BELO HORIZONTE. Prefeitura Municipal de Belo Horizonte. Superintendência de Desenvolvimento da Capital (Ed.). Plano de Controle Ambiental do Boulervad Arrudas: $5^{\circ}$ Trecho. 2014. Aluvial Engenharia e Meio Ambiente Ltda. Disponível

em: http://portalpbh.pbh.gov.br/pbh/ecp/comunidade.do?evento=portlet\&pIdPIc=ec pTaxonomiaMenuPortal\&app=transparenciacopa2014\&lang=pt_BR\&pg=9841\&ta x=26881 Acesso em: 28 mar. 2014.

BRASIL. Instituto Brasileiro de Geografia e Estatística. Brasil. Censo demográfico de 2010. 2012. Disponível em: http://censo2010.ibge.gov.br/. Acesso em: 25 jun. 2014. 
CARDOSO, A. S.; BAPTISTA, M. B. Metodologia para avaliação de alternativas de intervenção em cursos de água em áreas urbanas, Revista Brasileira de Recursos Hídricos, Porto Alegre, v. 16, n.1, p, 129-139, 2009.

CARDOSO, L. Transporte público, acessibilidade urbana e desigualdades socioespaciais na Região Metropolitana de Belo Horizonte. 2007. 218 f. Tese (Doutorado) - Curso de Geografia, Programa de Pós-graduação em Geografia, Universidade Federal de Minas Gerais, Belo Horizonte, 2007.

COSTA, H. S. de M.; BONTEMPO, V.; KNAUER, S. Programa DRENURBS: uma discussão sobre a constituição de alianças de aprendizagem na Política de Saneamento de Belo Horizonte. In: ENCONTRO NACIONAL DE ESTUDOS POPULACIONAIS, 14, 2008, Caxambu. Anais... . Caxambu: Abep, 2008. p. 1 $15 . \quad$ Disponível em: http://www.abep.nepo.unicamp.br/encontro2008/docsPDF/ABEP2008_1146.pdf Acesso em: 26 jun. 2014.

CHRISTOFOLETTI, A. Geomorfologia: análise de Bacias Hidrográficas. $2^{a}$ edição. São Paulo: Edgard Blucher, 1980. 97p.

LUCAS, T. de P. B. Chuvas persistentes e ação da zona de convergência do Atlântico Sul na Região Metropolitana de Belo Horizonte. 2007. 158 f.

Dissertação (Mestrado) - Curso de Geografia, Programa de Pós-graduação em Geografia, Universidade Federal de Minas Gerais, Belo Horizonte, 2007.

MINISTÉRIO DAS CIDADES - INSTITUTO DE PESQUISAS TECNOLÓGICAS. Mapeamento de riscos em encostas e margem de rios. Brasília: Ministério das Cidades; Instituto de Pesquisas Tecnológicas - IPT, 2007. 176p.

NASCIMENTO, N. O; AROEIRA, R. Belo Horizonte Threats and Uncertainties. Belo Horizonte: Convênio PBH/Sudecap - UFMG, 2006. 38 p.

NIMER, E. Climatologia do Brasil. Rio de Janeiro: IBGE, 1979.

PAOLUCCI, C. O. Risco Hidrometeorológico no município de Belo Horizonte: eficiências e deficiências desde os anos 1990 e sua gestão. 2011. 143 f. Dissertação (Mestrado) - Curso de Geografia, Programa de Pós-graduação em Geografia, Universidade Federal de Minas Gerais, Belo Horizonte, 2011.

PARIZZI, M. G. Desastres naturais e induzidos e o risco urbano. Geonomos, Belo Horizonte, v. 22, n 1, p. 1-9, 2014.

PRUDENTE, C. N.; REIS, R. J. dos. Banco de Dados de Desastres Naturais em Belo Horizonte 1979 a 2009. In: SIMPÓSIO BRASILEIRO DE GEOGRAFIA FÍSICA, 13, 2009, Viçosa. Anais... . Viçosa: Ufes, 2009. v. 1, p. 1 - 11. CD-ROM.

REIS, P. E. O escoamento superficial como condicionante de inundação em Belo Horizonte, MG: estudo de caso da sub-bacia córrego do Leitão, bacia do ribeirão Arrudas. 2011. 148f. Dissertação (Mestrado) - Programa de Pós-graduação em Geologia, Universidade Federal de Minas Gerais, Belo Horizonte, 2011. 
SILVA, C. B. da. Mapeamento das áreas de inundação do Rio Ibirapuitã em Alegrete-RS. Geografia Ensino \& Pesquisa, Farroupilha, v. 3, n. 15, p.73-91, set./dez. de 2011. Disponível em: <cascavel.ufsm.br/revistas/ojs2.2.2/index.php/geografia/...>. Acesso em: 26 jun. 2014.

TUCCI, C. E. M.; BERTONI, J. C. Inundações urbanas na América do Sul. Porto Alegre: Associação Brasileira de Recursos Hídricos, 2003. 150 p. Disponível em: http://www.eclac.cl/samtac/noticias/documentosdetrabajo/5/23335/InBr02803. pdf. Acesso em: 25 jun. 2014.

Texto submetido à RBClima na data de 03/07/2014 